\title{
Synthesis \\ Using Matching Methods to Link Social and Physical Analyses for Sustainability Planning
}

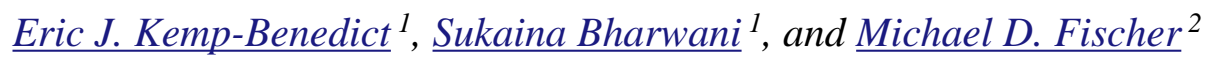

\begin{abstract}
Sustainability planning requires an understanding of social and physical systems and their interactions. However, there is a mismatch between the methods of the social sciences and those of the natural sciences. Although there have been numerous attempts to adapt the methods of the natural sciences for use in the social sciences, the results are usually unsatisfactory. Key features of societies such as institutions and power relationships, and of individuals such as the rich symbolic systems by which individuals transmit knowledge, do not lend themselves to the standard analytical methods of the natural sciences. We argue that rather than transfer the methods of one discipline to the other, an appropriate goal can be to seek "matching methods" that work at the boundary between the social and natural sciences. We discuss how knowledge elicitation tools (KnETs) can be used to develop matching methods. An explicit example is provided by combining a KnETs-derived decision tree with a physical water allocation model that was built using the scenario-based Water Evaluation and Planning (WEAP) software. We conclude that, through a relatively weak link, the social and physical domains can be effectively combined for integrated planning using matching methods, thereby permitting a more holistic approach to sustainable resource planning.
\end{abstract}

Key Words: decision making; integrated analysis; matching methods; natural resources; planning; sustainability science

\section{INTRODUCTION}

Sustainability planning seeks to balance human needs against the need for maintaining the health and viability of the natural environment. When considering how to support and enhance the livelihood possibilities of the poor, an important sustainability consideration is how current and potential livelihood strategies might affect resources. An effective analysis must therefore consider the social dynamics guiding the individuals and groups who have relationships with their environment, and it must consider the physical processes by which the natural resources-such as water, energy, and land-are conveyed, transformed, and used.

Anyone embarking on such a study quickly faces the lack of correspondence between the methods of the social sciences and the natural sciences. The natural sciences involve comparatively more stringent techniques for hypothesis testing, verification, and validation, while the social sciences use complex dynamics and confounding effects that introduce both variability and uncertainty into observed phenomena. The differences are not due to the faults or the virtues of the practitioners in these fields, but to the subject under study. Any study that seeks to understand coupled socio-ecological systems must face the intrinsic difficulty of studying people.

The approach pursued in this paper is to allow both the social scientist and the natural scientist to use the methods with which he or she is most comfortable. The task then becomes a search for "matching methods" that work at the boundary between the social and natural sciences. We discuss how knowledge elicitation tools (KnETs), which are based in the social sciences, can be combined with 
a physically based analytical tool as a matching method.

Variations on the approach to reconciling social and physical models presented in this paper have been reported by Berkes and Folke (1998), Lynam et al. (2007), and Letcher et al. (2006), and by researchers using agent-based modelling and Bayesian approaches. Although the use of agent-based models in the social sciences is still relatively new, and in need of development (Kohler 2000), considerable progress is being made to include stakeholder participation and expert knowledge under the rubric of Companion Modelling (Barretau et al. 2003, Gurung et al. 2006). This has been extended through other role-playing elicitation techniques (Ziervogel et al. 2005), and by using output from the KnETs process to verify and validate expert knowledge and to populate the agents in an agent-based model (Bharwani 2004, Bharwani et al. 2005, Ziervogel et al. 2006). Bayesian networks have also been used to express and elicit behavioural models in environmental planning (Bromley 2005, Varis 2002).

While this paper focuses on the bridge between social and physical models, rather than the process of creating the models, it should be recognized that the process of building models contributes importantly to the legitimacy of the model produced, depending on how open the process is. Substantially participatory exercises include those described in Argent et al. (1999), Argent and Grayson (2003), Barretau et al. (2003), Calder (2004), Costanza and Ruth (1988), and Loucks et al. (1996). An ongoing participatory process can (and, in the view of the authors, should) be used in the implementation of the approach described in this paper.

This paper uses a water planning environment for purposes of demonstration. However, the basic framework should be relevant for a wide range of issues related to sustainable livelihoods, beyond those issues that are most visible in the water sector alone. In particular, it should be possible to use this approach with little modification for energy and land-use planning. Because these various sectors intersect, the use of a common matching method between social and physical domains could assist in carrying out joint analyses of water, energy, and land use, and their contributions to livelihoods.

\section{MATCHING METHODS}

An effective "matching method" provides a link between a social scientific description of a part of a system and a physical description of a part of the same system. To do this, a matching method must mediate between a social science model and a natural science model, and must therefore provide the necessary inputs, and accept the outputs, of each type of model while respecting the distinctive features of the modeling approaches in each domain. The link could be dynamic or static. With a dynamic link, the models are run simultaneously, and information is actively transferred back and forth. With a static link, one model is run first, and the output is used as an input to the other model, which is run subsequently. In the demonstration provided in this paper, a dynamic link is created.

Models in both the natural and social sciences generally feature some deterministic elements; uncertainty is also present to a greater or lesser degree. When adapting either physical or social models that have been tested in the laboratory or in controlled studies to real-world situations, the role of uncertainty rises significantly. The point of controlled and laboratory studies, after all, is to isolate specific features of the system under study in order to answer very specific questions. In the world of policy and planning, the system cannot be isolated, and key model parameters cannot be decisively calculated (Oreskes 1998, 2003). This highlights a further common feature of social science and natural science models, especially in the policy domain - that of contingency. The behavior of the system is contingent on local conditions and historical processes. This makes the job of model validation a challenging exercise.

In addition to these common features, there are distinctive elements of models in the social and natural sciences. At the broadest level, models of social systems are frequently qualitative, or have important qualitative elements, while natural science models are mostly quantitative. In many situations this is not a serious problem, because the qualitative categories that emerge from social scientific investigations can be translated into quantitative terms, or can be compared against each other to form a ranked hierarchy of options, and there are standard approaches for manipulating such data (Kaplan 2004). For example, qualitative 
categories such as "dry year" and "wet year" that may be used by an informant in a study can be translated into (fuzzy) ranges of annual or seasonal precipitation, while ranking assignments such as "much more important", "less important", etc. can either be translated into values on a numerical scale or given a relative rank. Alternatively, it is sometimes possible to link qualitative states probabilistically - that is, given that one part of the system is in one qualitative state, there may be a corresponding probability that another part of the system is in another qualitative state. With such associations, qualitative categories can be mapped to quantitative values (Bromley 2005, Pearl 2001), though this is subjective, and requires assumptions regarding the relation between informant judgements of probability or likelihood and the actual frequencies of occurrence (O'Hagan 2006).

More serious discrepancies appear when probing the dynamics of social systems-that is, the processes that drive and constrain changes in systems. Three features prevalent in social systems are the role of autonomy and agency, the layered nature of social dynamics, and the possible nature of social systems as complex adaptive systems (CAS). These will be considered one at a time.

\section{Autonomy and agency}

Although research in cognitive science and artificial intelligence has made strides toward understanding the physical basis of human intelligence, no current or envisioned biophysical model can explain the vicissitudes of human will. A model intended for policy must start with human autonomy and agency as givens, and in any situation, it can be expected that people or households will display any of a range of possible behaviors. Combined with the importance of socially specific ("emic") categories of thought, and the role of tacit knowledge (Harris 1979, Gladwin 1989), this consideration may lie behind the difficulty of matching rational choice models with empirical observation, at least in the political realm (Green and Shapiro 1994). The range of possible behaviors is not infinite-human agency is bounded by physical constraints, social norms, family behaviors, and physiological endowments. However, the range can be large and the interactions of these elements, complex.

\section{Layers of meaning}

A second challenge with matching social and natural science models is that people act at different levels of meaning, so that social dynamics are layered. As Geertz famously pointed out (Geertz 1973), even the simplest actions - such as winking - can have multiple and layered meanings. Other authors (e.g., Bailey 1988) have pointed to the multiple cultural strands that people respond to: as individuals view themselves through one cultural lens or another, their behavior changes accordingly. A conceptual or mathematical model that relies on behavior at only one level (say, the economic) will miss critical dynamic processes that act at other levels (Slaughter 2004, Inayatullah 2002).

Approaches to eliciting the inputs to societal models should respect these layers of meaning. Knowledge elicitation tools (KnETs) are designed to provide such inputs, because KnETs are built around the ethnographic interview (Ellen 1984, Spradley 1979) in which the interviewer endeavours to elicit the cultural frame of reference of the informant.

\section{Social systems as complex adaptive systems}

Societies share many aspects of complex adaptive systems (CAS) (Miller and Page 2007, Rihani 2002; see also Berkes 2007, Costanza et al. 1993). In a CAS, interactions between system components are non-linear. Macroscopic behavior of the system is sometimes described as "emergent" in that it is expressed only when parts of the system interact, and cannot be inferred from local dynamics. Depending on the values of a relatively small number of parameters, any given CAS can exist in a wide variety of macroscopic states. Smooth changes in parameters can move the system into a situation in which the current macroscopic state is no longer stable, in which case it can transition into a newly stable macroscopic state. Thus, from the point of view of an observer of a CAS, the system can begin an apparently inexorable change into a new configuration with little warning. In physical CAS, the dynamics are well-defined, but the macroscopic expression of those dynamics can be surprising and it can be difficult-even impossible - to predict. In social systems, especially in a policy context in which novel behavior is expected, such surprising transitions pose a fundamental challenge for planning. 


\section{KNOWLEDGE ELICITATION TOOLS}

Knowledge elicitation tools (KnETs) are an approach and a set of tools for eliciting cultural, social, and tacit knowledge from domain experts. KnETs have been applied to farming communities in the United Kingdom: in East Kent to explore cropping decisions based on climate change (Bharwani 2004), and in Suffolk to look at decision criteria driven by irrigation quota and licensing criteria (Weatherhead et al. 2005). In Limpopo Province in South Africa (Ziervogel et al. 2006) KnETs have been used to explore the crop choices of small-scale subsistence farmers in a community garden project where there is an unreliable source of irrigation but good seasonal forecast information. The output of this process - a set of decision rules - was then incorporated in an agent-based model representing decision making at the household level, to further explore the dynamics of the system (Bharwani et al. 2005). The approach is also being used in the European Commission NeWater project [1], and it is being compared in the Orange (Lesotho), Upper Guadiana (Spain) and Tisza (Hungary and the Ukraine) river basins.

The approach draws on the techniques and insights of ethnographic research, knowledge engineering, and artificial intelligence (AI). The task is to capture the cultural models that are employed by social actors when responding to their environment, in order to represent them in a formal way as part of a sustainability assessment. The approach is similar in spirit to companion modeling (Barretau et al. 2003, Barreteau et al. 2001), in which stakeholders and local actors collaborate to create agent-based models that represent their behaviors under different circumstances. The KnETs process is based on an innovation in knowledge engineering by Wooten and Rowley (1995), who used Wood and Ford's (1993) ethnographic interview model as a starting point. Wooten and Rowley adapted the ethnographic interview to knowledge engineering. Carrying out an ethnographic interview requires the interviewer to pose questions within the cultural frame of reference of the informant, and therefore requires the interviewer to elicit not only answers but also questions from informants (Ellen 1984, Spradley 1979). This process enables the anthropologist to broach the realm of tacit knowledge and make inferences based on what is said and observed without being influenced by his or her own cultural assumptions. Furthermore, it is the role of the ethnographer or knowledge engineer to make generaliations and abstract statements based on these inferences, without distorting the terminology of the informant by expecting them do so. Part of the ethnographic process is knowing what questions to ask. However, formulating questions requires derivation from one's own cultural frame of reference, which may be different from the frame of reference the respondent uses to provide answers, and thus distortion can emerge. Therefore, in ethnographic interviewing both questions and answers must be discovered from informants (Ellen 1984, Spradley 1979). This is the significant difference between the interview that may be conducted by the journalist, and the ethnographic interview, where the former imposes a question based on a framework that is possibly very different from that of the domain expert (Ellen 1984). Furthermore, the latter can often result in the discovery of new and unexpected areas as a basis for study as a result of "tuning in" to local discourse in order to discover issues that enable the ethnographer to ask competent questions which will be meaningful to the informant (Ellen 1984). Such a process provides more substantive insights into an informant's cultural model than does an interview based on the interviewer's frame of reference and his or her underlying cultural assumptions.

KnETs introduce a further innovation that can be thought of as an elaboration on the standard concurrent verbalization method of knowledge engineering, in which the informant "thinks aloud" about what he or she knows (McGraw and HarbisonBriggs 1989). KnETs structures the concurrent verbalization by focusing informants on a sequence of (informant-derived) "scenarios", or collections of prompts for different conditions. (These scenarios are more focused, but less wide ranging than the scenarios produced in a participatory scenario exercise: see Slaughter 2004, Bishop et al. 2007.) The KnETs process follows the steps outlined in Fig. 1.

Open-ended and exploratory fieldwork (Fig. 1) is followed by the development of a more focused and structured interactive game, which is developed in the KnETs software (Fig. 2). In the course of playing the game, the informant is taken through a large number of scenarios that are derived from variables provided by informants during the fieldwork phase. Therefore, as explained above, the game and resulting scenarios are formed using the informant's own frame of reference; and, as a result, every game will be different because the actors and the context 
Fig. 1. Steps in the KnETs process

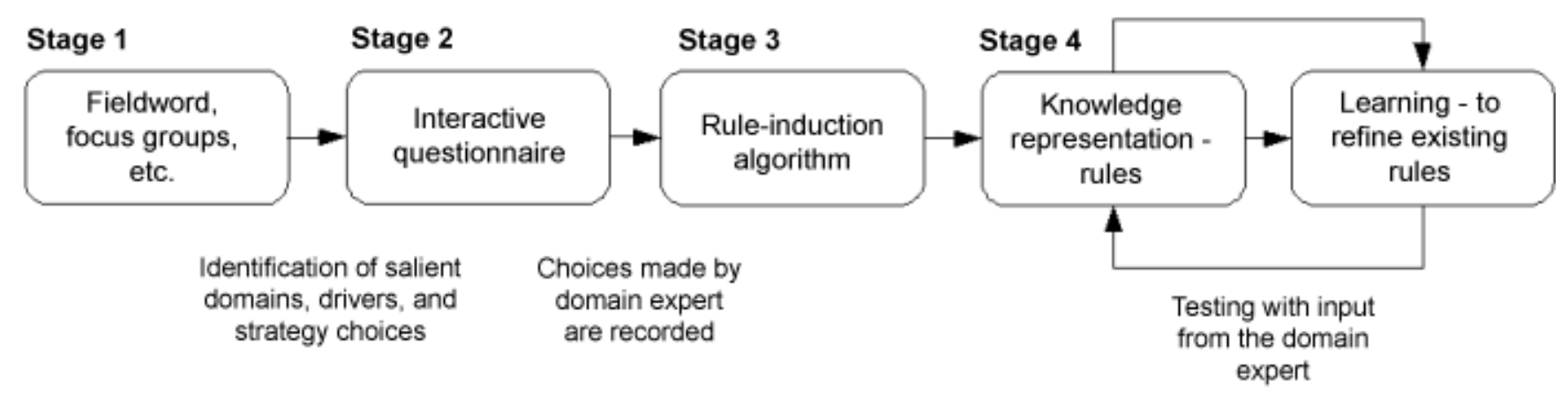

will be differernt in each case. The informant then explains what he or she would do under the circumstances described and this is recorded.

After a large number of runs (the number of runs depends on the number of variables the informant has mentioned as being important to the decision), an algorithm is applied to the responses in order to find a parsimonious decision tree that represents the decision-making process. The current KnETs software uses, by default, an implementation (J48) of the C4.5 learning algorithm (Quinlan 1993). The C4.5 algorithm uses an information entropy criterion for taking the unclassified set of responses from the informant and splitting them into a series of yes/no decisions as a decision tree. Different possible splits are tested, and the one that results in the greatest increase in information is selected. The process is then applied iteratively to the two subtrees generated by each split, until the entire set of responses is placed into the decision tree. The decision tree takes information about the environment and, through the series of yes/no questions, narrows down to a single response. A partial decision tree is shown in Fig. 3. In this example tree, an environment in which the soil is light, the climate is warmer, and overseas production is poor would lead the informant to a decision to plant vegetables.

Figure 3 is an example of a decision tree that includes some emic (cultural) criteria. The KnETs process does not end with the automated construction of the decision tree. As shown in Step 4 in Fig. 1, the interviewer takes the automatically produced decision tree (the knowledge representation rules) as a starting point, but then uses his or her own insight and continued interaction with informants and others to refine the decision tree. An important aspect of this further work is to capture the motivation for taking various actions. From the results of the game, the KnETs interviewer develops several decision trees outside of the KnETs software itself-for example, on paper-and then tests the different trees by conducting further interviews. This allows the interviewer to fill gaps in the knowledge elicited and, most importantly, to access the realm of tacit knowledge, which is difficult to do using ordinary interview techniques (Bharwani 2006).

\section{MATCHING TO A PHYSICAL MODEL}

The thesis in this paper is that "matching methods" can be used to link social-scientific models with models from the physical sciences. The goal with such matching methods is that the social scientist can use the methods that are most congenial to him, while the physical scientist can use the techniques that she finds most familiar. To make this idea more explicit, a demonstration model was constructed. The demonstration model uses one sample decision tree developed from interviews with farmers in South Africa and links it to a physical model of water flows using the Water Evaluation and Planning (WEAP) software (Yates et al. 2005a, 2005b). ${ }^{[2]}$ 
Fig. 2. KnETs interactive questionnaire

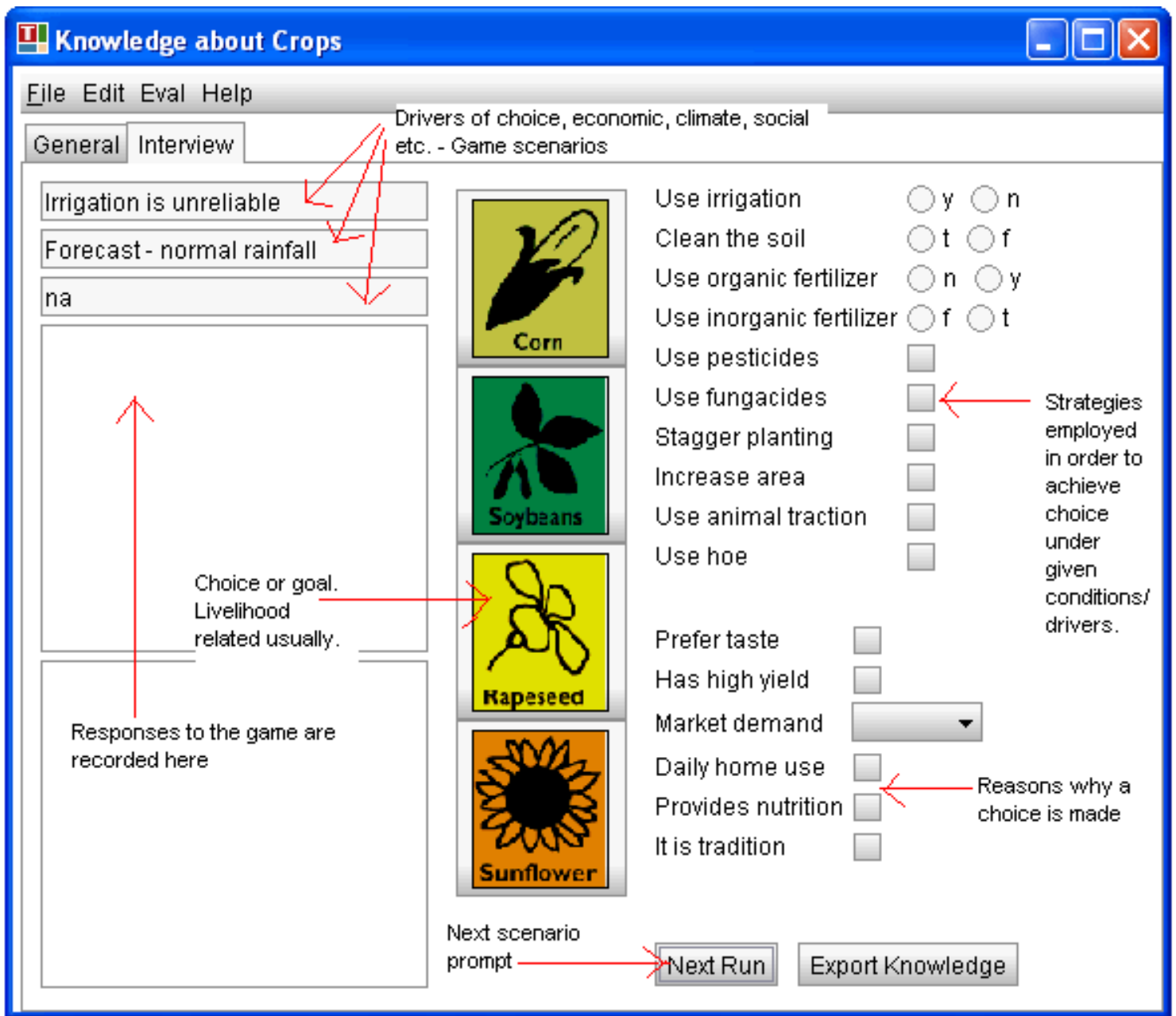

\section{The WEAP water planning model}

The Water Evaluation and Planning System (WEAP) is an integrated water resources management (IWRM) model. Its design is motivated by several goals. In terms of focus, it aims for a balanced approach to social and institutional aspects of water management (allocation, use, and distribution) and the physical aspects (the hydrology). Otherwise, it aims to be useful, easy to use, affordable, and readily available (Yates et al. $2005 \mathrm{~b}$ ). It is a scenario-based tool, in that it has special support for forward-looking studies, and allows the user to easily modify a handful of variables within a large model and study the effects of that change on key outputs such as water availability, flow through rivers, and groundwater levels.

WEAP has many built-in calculations, but also offers the modeler the option of user-specified variables and user-specified calculations. This feature of WEAP was used to implement the link between KnETs and WEAP. 
Fig. 3. Portion of a decision tree.

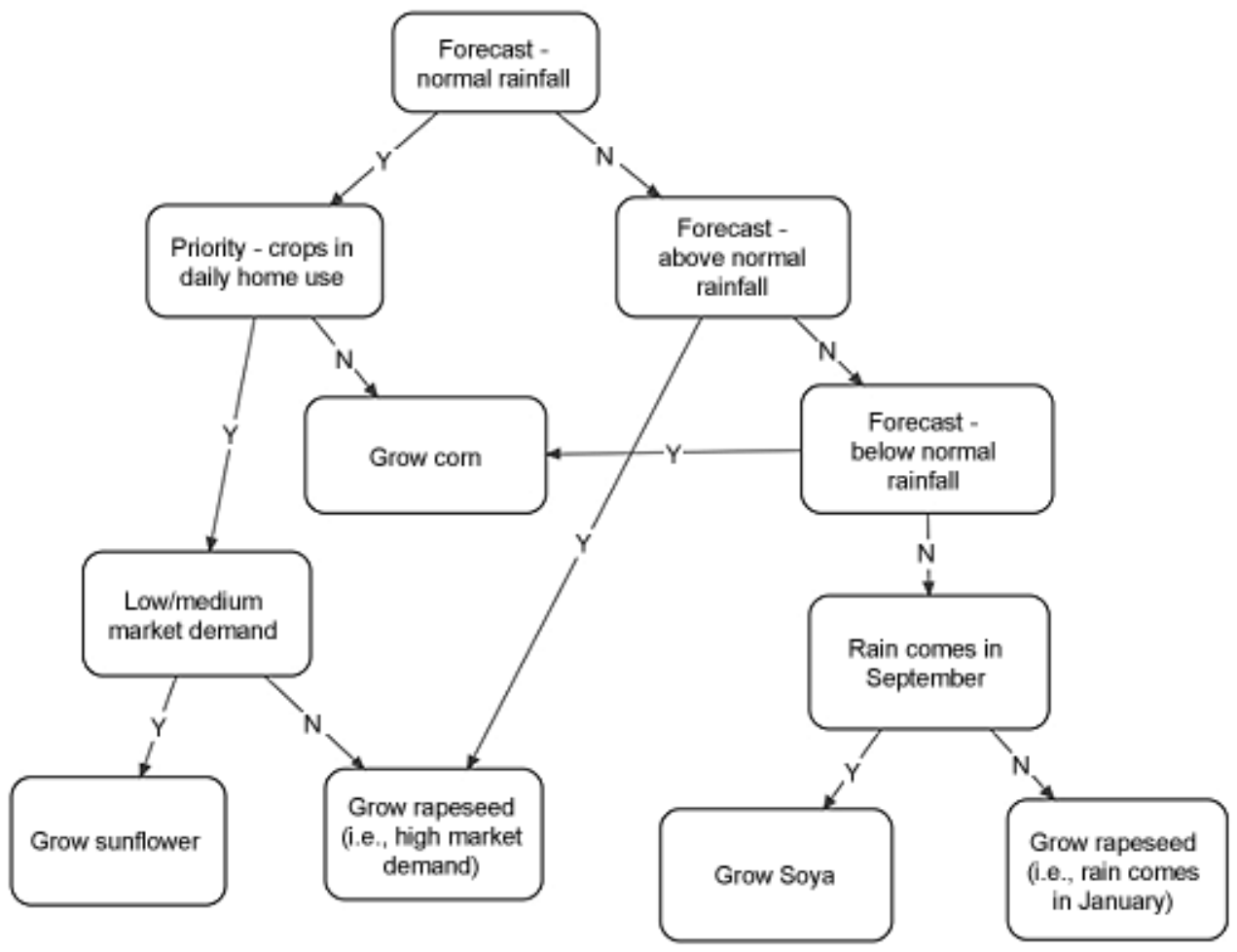

\section{Linking KnETs and WEAP}

In order to link KnETs with WEAP, some additional programming was thought necessary. A direct link between the KnETs software and WEAP was considered, but was rejected. One reason for this is that the final stages of the KnETs process (Fig. 1) require the interviewer to actively develop decision trees that are different from the tree automatically generated by the $\mathrm{C} 4.5$ algorithm. A second reason is that there is no natural matching between the variables in the decision tree and WEAP variables. Instead, the analyst must specify them. However, it was decided that a supporting tool could be created that would offer a decision tree building environment for the interviewer, while simplifying the task of matching variables in the decision tree to WEAP variables. The resulting tool, the decision tree builder, is shown in Fig. 4. ${ }^{[3]}$

As shown in Fig. 4, the decision tree builder interface allows the interviewer to develop decision trees, implemented as a series of yes/no questions. Each of the nodes in the tree is potentially related to a variable within a WEAP model for the system being described. Where no variable already exists, one can be introduced into WEAP. For example, "normal rainfall" may be related to the precipitation variable in a WEAP application, while "market demand" may be added to the WEAP model in order to further distinguish WEAP scenarios. The decision tree builder extracts each of the variables in the decision tree, and prompts the WEAP analyst for corresponding WEAP expressions. By combining these correspondences with the rules as expressed in the decision tree, the decision tree builder can generate a WEAP expression that implements the decision tree. The WEAP expression from the decision tree builder can be copied and pasted directly into a WEAP application.

For purposes of demonstration, this was done with a modified version of the "Weaping River" tutorial application that is distributed as part of the WEAP 
Fig. 4. Decision tree builder.

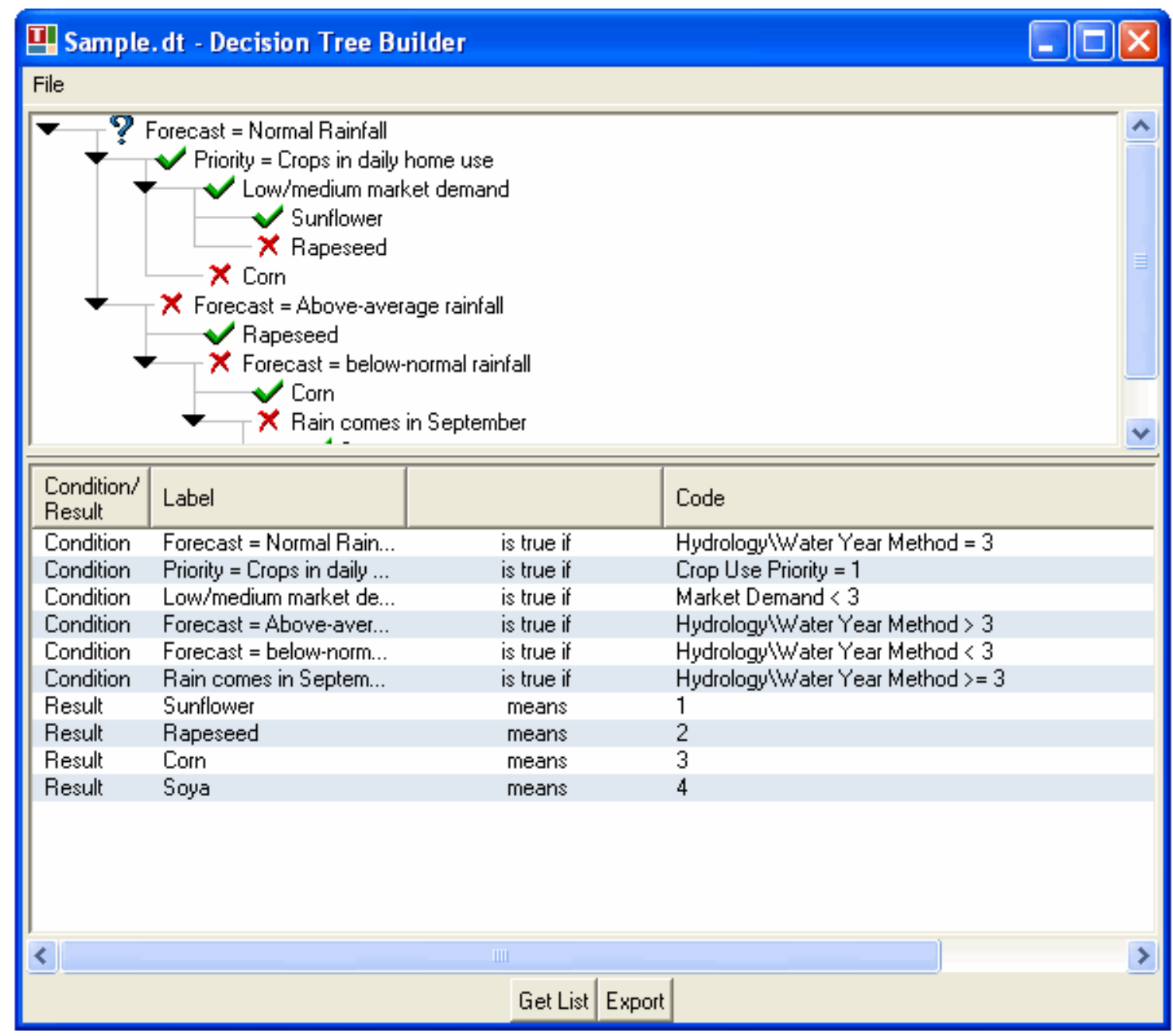

package. Weaping River is not an actual locale-it is used for demonstrating WEAP's features, for training, and as a reference for people developing their own WEAP models. The Weaping River application was modified by determining the headflow on the Weaping River through runoff and groundwater infiltration from a catchment. With the addition of the catchment object in WEAP, the headflow is determined by the hydrological processes in the catchment, in which water enters as precipitation and leaves as either surface runoff, evapotranspiration, or groundwater flow. The crop choice is affected, through KnETs, by the forecast for available precipitation, while crop choice itself affects evapotranspiration; and so, though the catchment hydrology, the KnETs link leads to a modification in the headflow. Two further scenario variables were also added, corresponding to variables in the KnETs decision tree: the priority for crops (assumed to be "home use" throughout each scenario) and the market demand for crops (assumed to be "medium" throughout each scenario). Different choices for those variables, which could represent alternative scenarios, would lead to different hydrological effects. The modified Weaping River network, with the additional 
Fig. 5. Modified Weaping River application

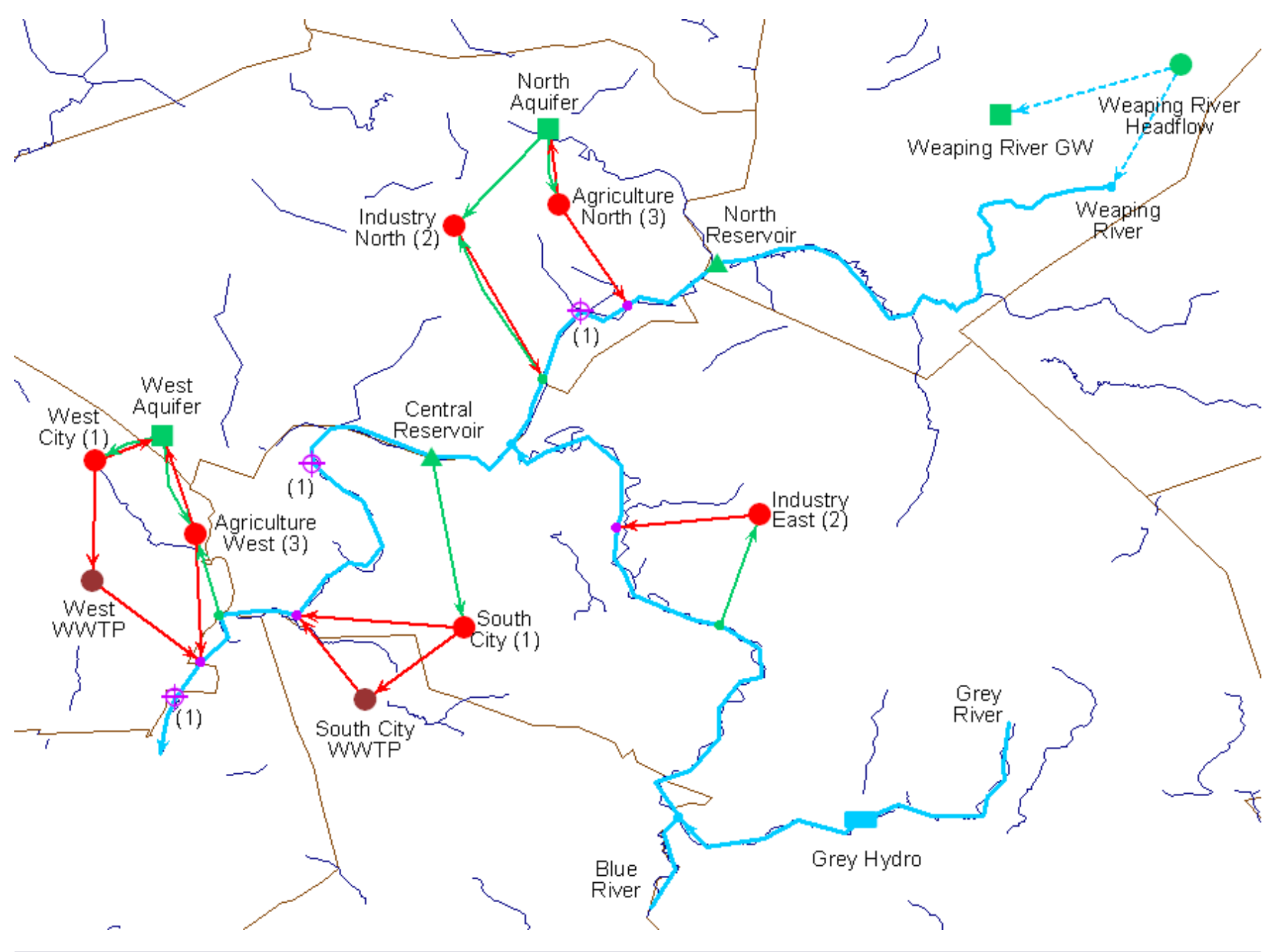

catchment and groundwater nodes ("Weaping River Headflow" and "Weaping River GW", respectively) is shown in Fig. 5.

In the newly added catchment node, farmers decide which crop to plant using the decision tree developed through the KnETs process and translated into a WEAP expression using the decision tree builder. In this simple example, this is an "all or none" decision, in which all farmers in the catchment plant the same crop each year. In a more realistic application, the result of the decision could be a crop mix, or different decision trees could be used to represent different types of farmers in the catchment. The result is shown in Fig. 6, where the choice of crop that emerges from the decision tree has a noticeable effect on the evapotranspiration from the catchment. Evapotranspiration for rapeseed is lower than that for sunflower, and evapotranspiration for corn is higher than that for sunflower. In none of the years was soya chosen as a result of evaluating the decision tree. The evapotranspiration in the catchment has an effect on the headflow to the Weaping River, as shown in Fig. 7 , and therefore for downstream water availability. While there is no feedback from the changed hydrology to the decision tree in the simple example used here, it is certainly possible that farmer decision could affect the watershed in such a way that the consequences of those decisions influence 
Fig. 6. Evapotranspiration due to crop choice

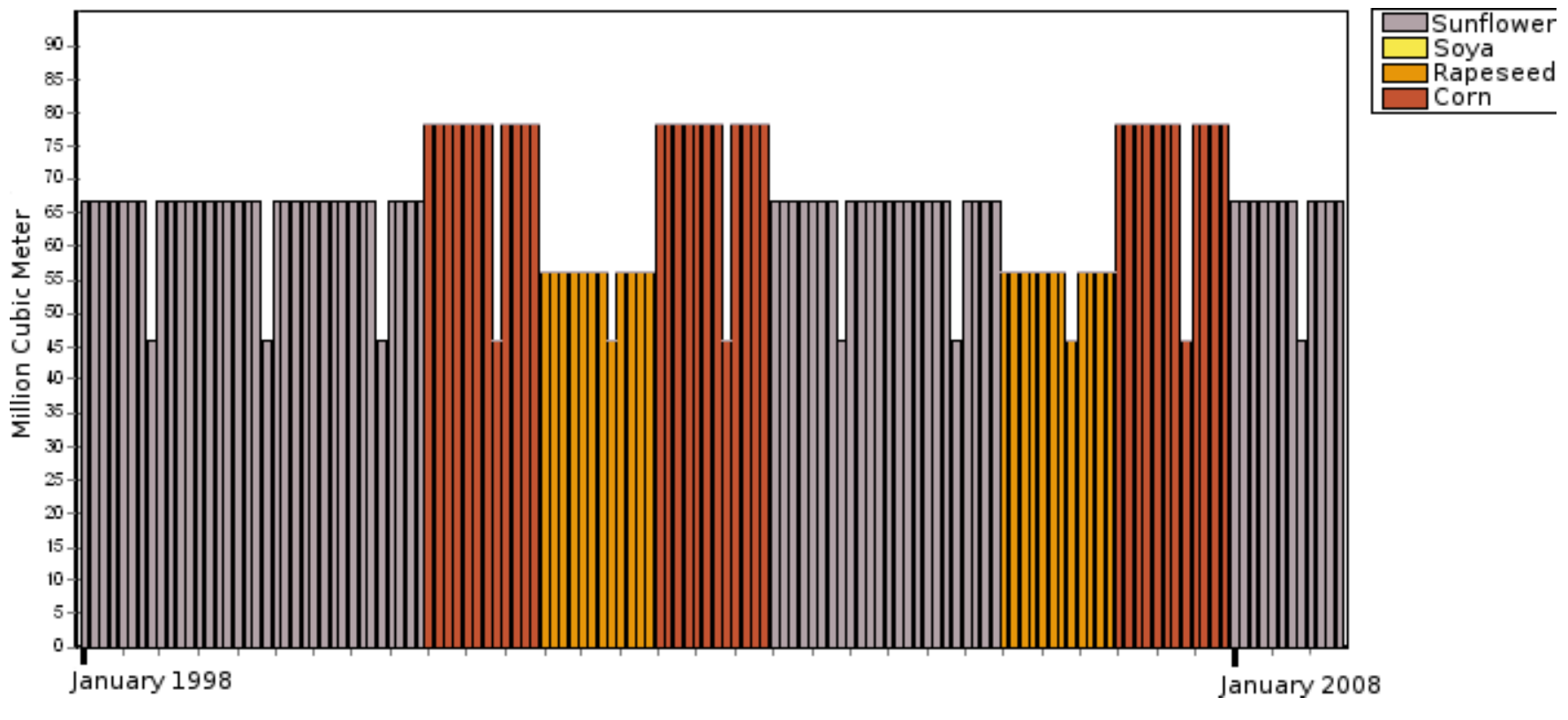

future farmer decisions, thus creating a feedback loop link between the decision tree and the WEAP application.

\section{Discussion}

Farmer and other human actions can significantly affect the hydrology of a catchment. Hydrological and water allocation scenario models must represent these actions in some fashion, and KnETs provide a uniquely informative approach to capturing and representing the decisions of farmers and other actors. As demonstrated with the KnETs-WEAP link described above, to the extent that farmers are influenced by physical variables present in a physical water model (in this case, a rainfall forecast), and make choices that affect physical outcomes (crop choice, with consequences for evapotranspiration), the decision model that KnETs provide can be combined with the physical model to capture the feedback between the physical and the social systems.

A further advantage of the process outlined above is that the link between KnETs and WEAP is minimal, which is essential for a "matching method" as proposed in this paper. Considerable work can be carried out separately by the social scientist, using KnETs in the field, and by the physical modeler, representing hydrological processes and physical water flows through a distribution network. The link between the social and physical systems is created by matching the decision tree produced from the KnETs process to variables and statements in the physical model, as shown in Fig. 4. This weak coupling allows the social scientist to use the methods most familiar to him, and for the physical scientist to use the tools and techniques with which she is most familiar. The tool illustrated in Fig. 4 acts as a boundary object between the disciplines where the social and physical scientists can discuss the relationship between the variables and statements in their separate representations.

\section{CONCLUSION}

Sustainability planning requires a combination of models from the social sciences and the physical sciences. We have argued that an effective way to do this is via "matching methods" that mediate between the two types of models. Such matching methods can allow practitioners in either the social 
Fig. 7. Percent difference in headflow, with decision tree vs. only sunflower

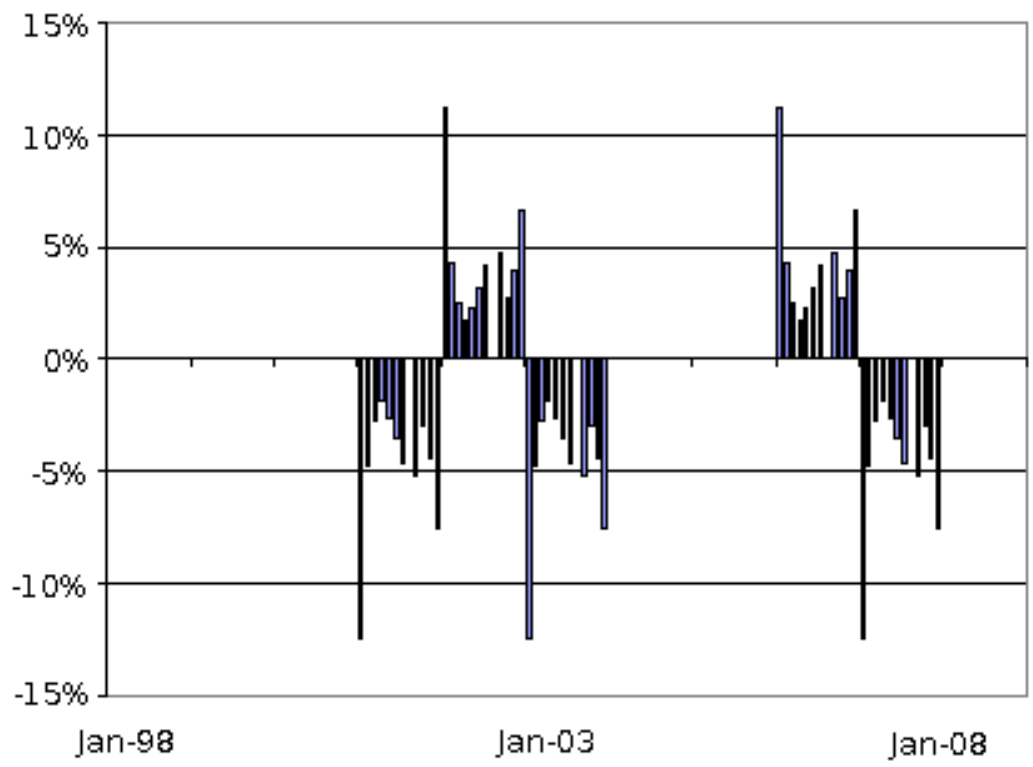

or physical sciences to use familiar approaches, with the dialog between practitioners taking place in a way that does not require them to learn an entirely new set of methods.

In order to demonstrate the approach, the knowledge elicitation tools (KnETs) process was combined with a scenario-based physical water planning model (WEAP). KnET uses computer learning to support an anthropological interview. Through the anthropological interview, the interviewer avoids placing an interpretive frame on informants' responses (Ellen 1984, Spradley 1979). The resulting representation of actors' decision making is much richer than that normally available to a physical modeler, who would typically resort either to fixed behavioral patterns or to rational choice models.

To implement the "matching" between the two tools, an additional software tool was developed, $i$. e., the decision tree builder. The decision tree builder provides a boundary object around which the social and physical scientist can meet and discuss the relationship between variables, concepts, and statements in their respective domains. The KnETs interviewer uses the decision tree builder to devise a decision tree that represents his or her understanding of decision-making processes within a community, while the WEAP modeler uses the decision tree builder to assist him or her in generating a WEAP expression that implements the decision tree in WEAP, thus allowing the WEAP model to dynamically incorporate the behavioral model represented by the decision tree that emerges from the KnETs process.

A modest example was constructed for purposes of demonstration. The results are plausible and interesting: changes in WEAP variables lead, via the KnETs-derived decision tree, to behavior that modifies the hydrology in subsequent time steps. These environmental changes could also conceivably be re-implemented in a new KnETs game to gauge the responses of informants to altered resource availability. The implementation allows social and physical scientists to work substantially with tools that are comfortable to them. The result is a linked social and physical model that captures decision making in terms that the informants themselves define, while providing concrete physical feedback to the social model that could affect subsequent decisions. 
The techniques presented in this paper, and the broader concept of "matching methods", demonstrate how a more holistic link to sustainable resource planning can be achieved and used to evaluate the effects of interventions on people's livelihoods. The conceptual framework and example presented in this paper show how a relatively weak link between the social and physical domains can support a significantly more integrated planning approach that combines the social and physical sciences into a holistic approach.

Responses to this article can be read online at:

http://www.ecologyandsociety.org/voll5/iss3/art4/responses/

\section{Acknowledgments:}

The authors would like to acknowledge David Michaud for collecting information about decisionsupport systems and Chris Swartz for undertaking a close reading of the draft manuscript. All errors are our own.

\section{LITERATURE CITED}

Argent, R. M., and R. B. Grayson. 2003. A modelling shell for participatory assessment and management of natural resources. Environmental Modelling and Software 18(6):541-551.

Argent, R. M., R. B. Grayson, and S. A. Ewing. 1999. Integrated models for environmental management: issues of process and design. Environment International 25(6-7):693-699.

Bailey, F. G. 1988. Humbuggery and manipulation: the art of leadership. Cornell University Press, Ithaca, New York, USA.

Barretau, O., M. Antona, P. d'Aquino, S. Aubert, S. Boissau, F. Bousquet, W. Daré, M. Etienne, C. Le Page, R. Mathevet, G. Trébuil, and J. Weber. 2003. Our companion modelling approach. Journal of Artificial Societies and Social Simulation 6(2):1. [online] URL: http://jasss.soc.surrey.ac.uk/6/2/1.html

Barreteau, O., F. Bousquet, and J.-M. Attonaty. 2001. Role-playing games for opening the black box of multi-agent systems: method and teachings of its application to Senegal River Valley irrigated systems. Journal of Artificial Societies and Social Simulation 4(2):5. [online] URL: http://jasss.soc.su rrey.ac.uk/4/2/5.html.

Berkes, F. 2007. Understanding uncertainty and reducing vulnerability: lessons from resilience thinking. Natural Hazards 41:283-295.

Berkes, F, and C. Folke. 1998. Linking social and ecological systems for resilience and sustainability. Pages 1-26 in F. Berkes and C. Folke, editors. Linking social and ecological systems: management practices and social mechanisms for building resilience. Cambridge University Press, Cambridge, Cambridgeshire, UK.

Bharwani, S. 2004. Adaptive knowledge dynamics and emergent artificial societies: ethnographically based multi-agent simulations of behavioural adaptation in agro-climatic systems. Dissertation. University of Kent, Canterbury, Kent, UK.

Bharwani, S. 2006. Understanding complex behavior and decision making using ethnographic knowledge elicitation tools (KnETs). Social Science Computer Review 24(1):78-105.

Bharwani, S., M. Bithell, T. E. Downing, M. New, R. Washington, and G. Ziervogel. 2005. Multiagent modelling of climate outlooks and food security on a community garden scheme in Limpopo, South Africa. Philosophical Transactions of the Royal Society B. 360: 2183-2194.

Bishop, P., A. Hines, and T. Collins. 2007. The current state of scenario development: an overview of techniques. Foresight 9(1):5-25.

Bromley, J. 2005. Guidelines for the use of Bayesian networks as a participatory tool for water resource management: based on the results of the MERIT project. Management of the Environment and Resources Using Integrated Techniques (MERIT), project for the European Union 117, Centre for Ecology and Hydrology, Wallingford, Oxfordshire, UK.

Calder, I. R. 2004. Forests and water - closing the gap between public and science perceptions. Water Science and Technology 49(7):39-53.

Costanza, R., and M. Ruth. 1988. Using dynamic 
modeling to scope environmental problems and build consensus. Environmental Management 22 (2):183-195.

Costanza, R., L. Wainger, C. Folke, and K.-G. Mäler. 1993. Modeling complex ecological economic systems. BioScience 43(8):545-555.

Ellen, R. F., editor. 1984. Ethnographic research: a guide to general conduct. Academic Press, London, UK.

Geertz, C. 1973. Thick description: toward an interpretive theory of culture. Pages 3-30 in The interpretation of cultures: selected essays. Basic Books, New York, New York, USA.

Gladwin, C. H. 1989. Ethnographic decision tree modelling. Save Publications, Beverly Hills, California, USA.

Green, D. P., and I. Shapiro. 1994. Pathologies of rational choice theory: a critique of applications in social science. Yale University Press, New Haven, Connecticut, USA.

Gurung, T. R., F. Bousquet, and G. Trébuil. 2006. Companion modeling, conflict resolution, and institution building: sharing irrigation water in the Lingmuteychu Watershed, Bhutan. Ecology and Society 11(2):36. [online] URL: http://www.ecolo gyandsociety.org/vol11/iss2/art36/

Harris, M. 1979. Cultural materialism: the struggle for a science of culture. Random House, New York, New York, USA.

Inayatullah, S. 2002. Layered methodology: meanings, epistemes, and the politics of knowledge. Futures 34(6):479-491.

Kaplan, D. 2004. The Sage handbook of quantitative methodology for the social sciences. Sage Publications, Thousand Oaks, California, USA.

Kohler, T. A. 2000. Putting social sciences back together again: an introduction to the volume. Pages 1-18 in T. A. Kohler and G. J. Gumerman, editors. Dynamics in human and primate societies: agentbased modeling of social and spatial processes. Oxford University Press, New York, New York, USA.

Letcher, R. A., B. F. W. Croke, W. S. Merritte, and A. J. Jakeman. 2006. An integrated modelling toolbox for water resources assessment and management in highland catchments: sensitivity analysis and testing. Agricultural Systems 89:132-164.

Loucks, D. P., P. N. French, and M. R. Taylor. 1996. Development and use of map-based simulation shells for creating shared-vision models. International Association of Hydrological Sciences, Vienna, Austria.

Lynam, T., W. De Jong, D. Sheil, T. Kusumanto, and K. Evans. 2007. A review of tools for incorporating community knowledge, preferences, and values into decision making in natural resources management. Ecology and Society 12(1): 5. [online] URL: http://www.ecologyandsociety.org/vol12/iss1/ art5/.

McGraw, K. L., and K. Harbison-Briggs. 1989. Knowledge acquisition. Prentice Hall, Englewood Cliffs, New Jersey, USA.

Miller, J. H., and S. E. Page. 2007. Complex adaptive systems: an introduction to computational models of social life. Princeton University Press, Princeton, New Jersey, USA.

O'Hagan, A. 2006. Uncertain judgments: eliciting experts' probabilities. John Wiley and Sons, New York, New York, USA.

Oreskes, N. 1998. Evaluation (not validation) of quantitative models. Environmental Health Perspectives 106(Supplement 6):1453-1460.

Oreskes, N. 2003. The role of quantitative models in science. Pages 13-30 in C. D. Canham, J. J. Cole, and W. K. Lauenroth, editors. Models in ecosystem science. Princeton University Press, Princeton, New Jersey, USA.

Pearl, J. 2001. Causal inference in statistics: a gentle introduction. Pages 84-103 in E.J. Wegman, A. Braverman, A. Goodman, P. Smyth, editors. Computing Science and Statistics, Interface '01, Frontiers in Data Mining and Bioinformatics, Proceedings of the 33rd Symposium on the Interface, Costa Mesa, Orange County, California, June 13-16, 2001. Volume 33, Interface Foundation of North America, Fairfax, Vermont, USA. [online] URL: http://www.interfacesymposia.org/I01/master. pdf. And, Technical Report TR-289, Cognitive Systems Laboratory, Computer Science Department, 
University of California, Los Angeles, California USA. [online] URL: http://ftp.cs.ucla.edu/pub/stat_ser/ R289.pdf.

Quinlan, R. 1993. C4.5: programs for machine learning. Morgan Kaufmann, Burlington, Massachusetts, USA.

Rihani, S. 2002. Complex systems theory and development practice: understanding non-linear realities. Zed Books, London, UK.

Slaughter, R. A. 2004. Futures beyond dystopia: creating social foresight. RoutledgeFalmer, London, UK.

Spradley, J. P. 1979. The ethnographic interview. Rinehart \& Winston, New York, New York, USA.

Varis, O. 2002. Belief networks: generating the feared dislocations. Pages 162-176 in M. B. Beck, editor. Environmental foresight and models: a manifesto. Elsevier, Amsterdam, The Netherlands.

Weatherhead E. K., J. W. Knox, T. T. de Vries, S. Ramsden, J. Gibbons, N. W. Arnell, N. Odoni, K. Hiscock, C. Sandhu, A. Saich, D. Conway, C. Warwick, S. Bharwani, J. Hossell, and B. Clemence. 2005. Sustainable water resources: A framework for assessing adaptation options in the rural sector. Tyndall Centre Technical Report 44, Tyndall Centre for Climate Change Research, UEA, Norwich, Norfolk, UK.

Wood, L. E., and J. M. Ford. 1993. Structuring interviews with experts during knowledge elicitation. International Journal of Intelligent Systems 8(1):71-90.

Wooten, T. C., and T. H. Rowley. 1995. Using anthropological interview strategies to enhance knowledge acquisition. Expert Systems with Applications 9(4): 469-482.

Yates, D., D. Purkey, J. Sieber, A. Huber-Lee, and H. Galbraith. 2005a. WEAP21: A demand-, priority-, and preference-driven water planning model: part 2: aiding freshwater ecosystem service evaluation. Water International 30(4):501-512.

Yates, D., J. Sieber, D. Purkey, and A. Huber-Lee. 2005b. WEAP21: A demand-, priority-, and preference-driven water planning model: part 1: model characteristics. Water International $\mathbf{3 0}$
(4):487-500.

Ziervogel, G., S. Bharwani, and T. Downing. 2006. Adapting to climate variability: pumpkins, people and policy. Natural Resources Forum 30:294-305.

Ziervogel, G., M. Bithell, R. Washington, and T. Downing. 2005. Agent-based social simulation: a method for assessing the impact of seasonal climate forecasts among smallholder farmers. Agricultural Systems 83(1):1-26.

${ }^{[1]}$ Information available at http://www.newater.info/.

[2] WEAP is available from http://www.weap21.org/ . The current version (ver. 21) is referred to as WEAP21. While this is the version that was used for the calculations described in this paper, the generic name for the software, WEAP, will be used throughout.

[3] The decision tree builder program and a sample input file are available from ftp://sei-us.org/Decisio nTreeBuilder/. 